\title{
Surgery avoided by the use of over-the-scope clips for severe duodenal complications associated with endoscopic mucosal resection
}

During endoscopic treatment for duodenal neoplasm, hazardous complications such as perforation and bleeding sometimes occur owing to the anatomical characteristics of the duodenum [1-3]. Although surgical repair has been traditionally required for these complications, the procedure is invasive and complicated [4]. A currently available overthe-scope clip (OTSC; Ovesco Endoscopy, Tübingen, Germany) has provided excellent outcomes for gastrointestinal refractory bleeding and full-thickness defects [5]. Here, we describe a notable case in which iatrogenic duodenal complications could be managed with OTSCs. A 56-year-old man presented with a duodenal adenoma that showed a reddish and flat elevated lesion, approximately $10 \mathrm{~mm}$ in diameter, located in the posterior wall of the second duodenal portion ( Fig.1). After submucosal injection, cap-assisted endoscopic mucosal resection (EMR) was performed under carbon dioxide insufflation. A large full-thickness perforation, $20 \mathrm{~mm}$ in diameter, occurred ( Fig. 2 a), and spurting arterial bleeding was seen ( $\mathbf{F i g . 2} \mathbf{b}$ ). The bleeding was accompanied by hemorrhagic shock and was immediately controlled using hemo-

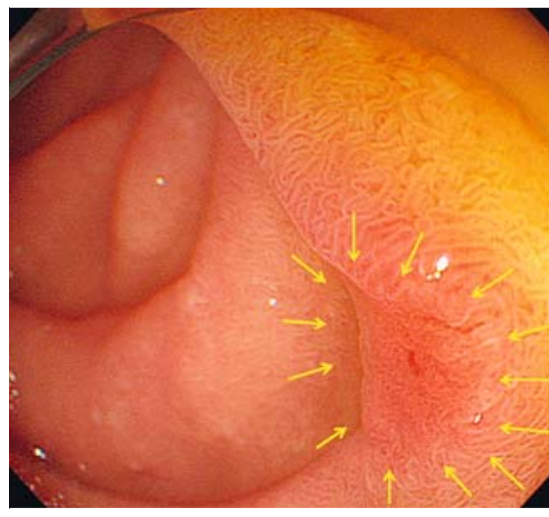

- Fig. 1 An upper gastrointestinal endoscopy revealed a reddish and flat elevated lesion (yellow allows), approximately $10 \mathrm{~mm}$ in diameter, located in the posterior wall of the second duodenal portion. static forceps (Coagrasper; Olympus, Tokyo, Japan). OTSCs were then applied to close the defect at the perforation site, after obtaining informed consent. Grasping forceps (Twingrasper; Ovesco Endoscopy) were used to approximate the edges of the large defect. The defect was mostly closed by one OTSC (t type,
$9 \mathrm{~mm})$, and the remaining defect was closed by an additional OTSC using simple suction ( $>$ Fig. 3 , > Video 1 ).

A radiographic examination 5 days later confirmed no leakage at the perforation site ( $>$ Fig.4). The patient was discharged without additional interventions 19 days later. A histological examination revealed

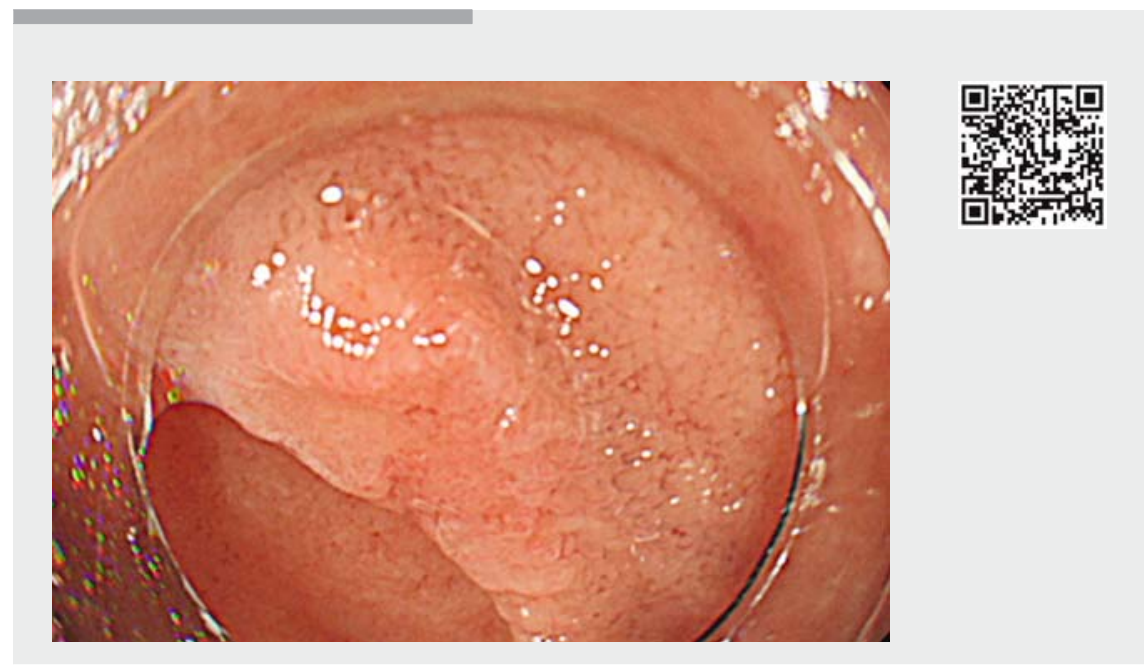

Video 1 Cap-assisted endoscopic mucosal resection was performed for a tumor located in the second duodenal portion. A large full-thickness perforation occurred with spurting arterial bleeding. After complete hemostasis was achieved using hemostatic forceps, the defect was successfully closed by two over-the-scope clips.
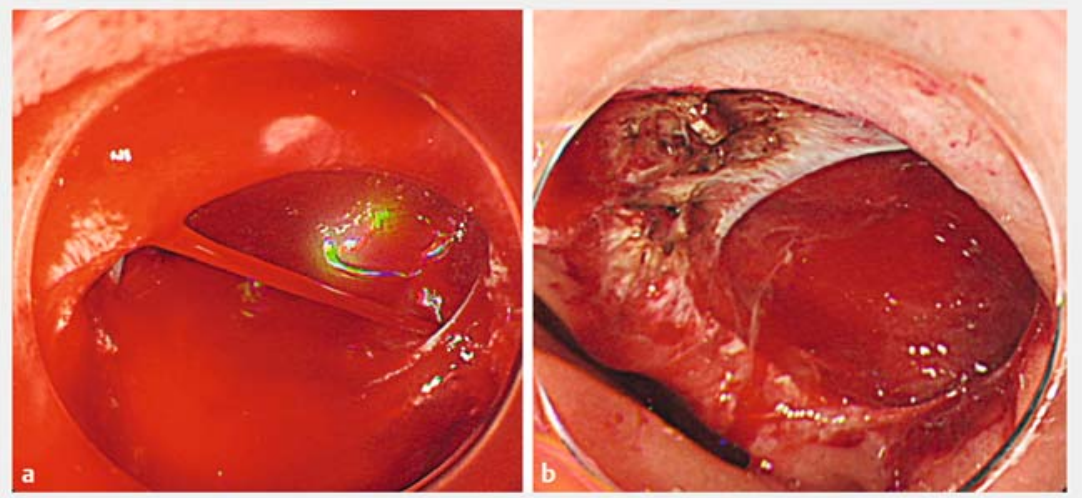

Fig. 2 Endoscopic views. a A large full-thickness perforation, $20 \mathrm{~mm}$ in diameter, occurred with exposure of the muscle layer after performing cap-assisted endoscopic mucosal resection. $\mathbf{b}$ Spurting arterial bleeding was seen at the edge of the perforation site. 


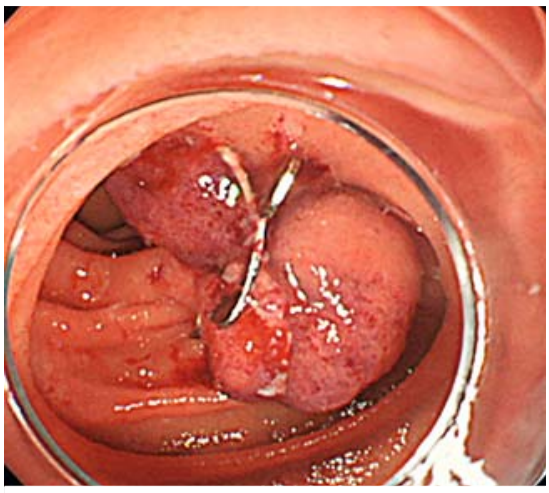

- Fig. 3 The whole defect was completely closed by two over-the-scope clips (t type, $9 \mathrm{~mm})$.

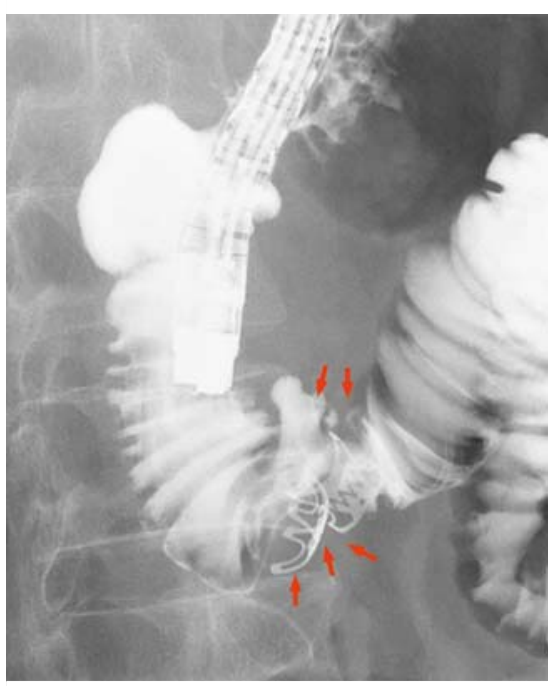

- Fig. 4 A radiograph confirmed no leakage at the perforation site 5 days later. The red arrows show the perforation site closed by over-the-scope clips.

curative resection of a tubular adenoma with moderate-grade dysplasia. Followup endoscopy 2 months later confirmed complete closure of the defect ( $\triangleright$ Fig. 5). This case demonstrates that OTSC rescue may be a minimally invasive therapy option for a life-threatening complication such as a large duodenal perforation with spurting bleeding.

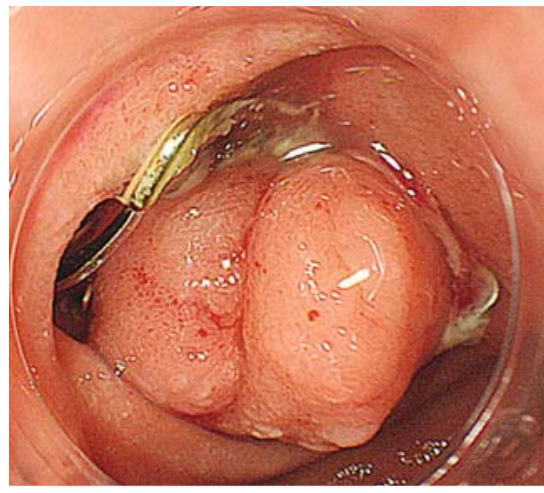

Fig. 5 Complete closure of the defect was confirmed 2 months later.

Endoscopy_UCTN_Code_CPL_1AH_2AZ

Competing interests

None

The Authors

Noriko Nishiyama, Hirohito Mori, Hideki Kobara, Shintaro Fujihara, Nobuya Kobayashi, Tatsuo Yachida, Tsutomu Masaki

Department of Gastroenterology and

Neurology, Faculty of Medicine, Kagawa

University, Kagawa, Japan

\section{Corresponding author}

\section{Noriko Nishiyama, MD, PhD}

Department of Gastroenterology and Neurology, Faculty of Medicine, Kagawa University, 1750-1 Ikenobe, Miki, Kita, Kagawa 761-0793, Japan

Fax: +81-87-8912158

n-nori@med.kagawa-u.ac.jp

\section{References}

[1] Nonaka S, Oda I, Tada K et al. Clinical outcome of endoscopic resection for nonampullary duodenal tumors. Endoscopy 2015; 47: $129-135$

[2] Hoteya S, Yahagi N, lizuka T et al. Endoscopic submucosal dissection for nonampullary large superficial adenocarcinoma/ adenoma of the duodenum: feasibility and long-term outcomes. Endosc Int Open 2013; 1: $2-7$

[3] Mori H, Ayaki M, Kobara H et al. Suitable closure for post-duodenal endoscopic resection taking medical costs into consideration. World J Gastroenterol 2015; 21: 5281 5286

[4] Farnell MB, Sakorafas GH, Sarr MG et al. Villous tumors of the duodenum: reappraisal of local vs. extended resection. J Gastrointest Surg 2000; 4: 13-21

[5] Haito-Chavez Y, Law JK, Kratt T et al. International multicenter experience with an over-the-scope clipping device for endoscopic management of $\mathrm{Gl}$ defects (with video). Gastrointest Endosc 2014; 80: 610 622

\section{Bibliography}

DOI https://doi.org/10.1055/s-0043-115891

Published online: 3.8.2017

Endoscopy 2017; 49: E279-E280

(c) Georg Thieme Verlag KG

Stuttgart · New York

ISSN 0013-726X

\section{ENDOSCOPY E-VIDEOS}

https://eref.thieme.de/e-videos

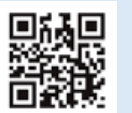

Endoscopy E-Videos is a free access online section, reporting on interesting cases and new

techniques in gastroenterological endoscopy. All papers include a high quality video and all contributions are freely accessible online.

This section has its own submission website at

https://mc.manuscriptcentral.com/e-videos 